\title{
Fetal Growth Retardation due to Maternal Tobacco Smoke Exposure in the Rat
}

\author{
JORGE A. BASSI, ${ }^{(28)}$ PEDRO ROSSO, ADRIEN C. MOESSINGER, WILLIAM A. BLANC, AND \\ L. STANLEY JAMES \\ Columbia University, College of Physicians and Surgeons. Institute of Human Nutrition, and Departments of \\ Pediatrics and Pathologl: New. York, New York USA
}

\begin{abstract}
Summary
Smoking during pregnancy results in offspring with an average birth weight $200 \mathrm{~g}$ less than those of non-smoking mothers. The pathogenesis of this effect is still unknown and there is no general agreement about the causal relationship between maternal smoking and subsequent fetal growth retardation. In the present study, a model of maternal smoking during pregnancy in the rat was established using the $P$ \& I Walton Exposure Machine. The study consisted of three groups: control, pair-fed, and smokeexposed. Smoke-exposed animals were exposed continuously to tobacco smoke for cycles of $7 \mathrm{~min}, 16$ times a day from $\mathrm{d} 5$ to $\mathrm{d}$ 20 of gestation. On d 21 of gestation, fetuses from all groups were removed by cesarean section, weighed, and dissected. The fetal brain, liver, and lungs as well as the placentas were weighed and analyzed for nucleic acid content. Fetal weight was found to be significantly reduced in both pair-fed and smoke-exposed groups compared with the control group. There was also a significant reduction in fetal body weight of the animals in the smoke-exposed group in comparison to those in the pair-fed group. Exposing the mother to smoke affected neither fetal brain weight nor nucleic acid content whereas fetal liver and lungs showed a significant decrease in both weight and nucleic acid content. These results indicate that the fetal growth retardation associated with maternal exposure to tobacco smoke in the rat corresponds to a disproportionate type. In addition, the present results indicate that the maternal tobacco smoke exposure induced fetal growth retardation without placental growth retardation.
\end{abstract}

Data from the literature clearly demonstrate that maternal smoking during pregnancy has a significant and adverse effect upon the fetus. Among other detrimental effects, smoking during pregnancy results in offspring with an average birth weight 200 $\mathrm{g}$ less than those of non-smoking mothers (20). The pathogenesis of this effect is still unknown and no general agreement exists about the causal relationship between maternal smoking and subsequent fetal growth retardation.

In attempts to elucidate the effect of maternal smoking on the fetus, pregnant experimental animals have been utilized in several different models, such as exposure to nicotine $(7,9,14,15$, $19)$, to smoke $(3,8,16,21,25)$, and to carbon monoxide and low oxygen environments (5). Although these studies have contributed to a better understanding of the effect of tobacco smoking, the intrinsic mechanisms as well as the specific pattern of the resulting fetal growth retardation still remain unclear.

Two major types of fetal growth retardation have been described (17), proportionate and disproportionate (also called "symetric" and "asymetric"). In the proportionate type, all organs decrease in weight to the same degree. In the disproportionate type the growth of the brain is relatively preserved in comparison to other organs. Clinical studies of infants of smoking mothers have not clarified which of the two types is associated with this condition (13).

The aim of the present study was 2-fold: first, to establish a reproducible model of maternal tobacco smoking in the rat, and second, to define the pattern of the fetal growth retardation.

\section{MATERIALS AND METHODS}

Mature, virgin female rats of the Sprague Dawley strain, 200 $250 \mathrm{~g}$ body weight, were used (Camm Company, Wayne, NJ). Cigarettes were tobacco, non-filter, $70 \mathrm{~mm}$ length. The total particulate matter less nicotine and water was $19.9 \pm 0.5 \mathrm{mg}$. Total alkaloids reported as nicotine were $1.11 \pm 0.03 \mathrm{mg}$.

The following instruments were used in the experiment: 1) $\mathrm{P}$ \& I Walton Smoke Exposure Machine, manufactured by Process \& Instruments Corporation, Brooklyn, NY and 2) IL 282 COOximeter, manufactured by Instrumentation Laboratory, Inc. Lexington, MA. The animal diet consisted of Rat-Mouse Diet $96 \mathrm{~W}$, pellets (protein, minimum: $19.0 \%$; fat, minimum: $7.5 \%$; fiber, maximum: $2.5 \%$; N.F.E., minimum: $52.0 \%$ ), Old Guilford Laboratory Animal Diets manufactured by the Emory Norse Co., Guilford, CT.

Animals were mated overnight. The next morning, vaginal smears were examined and the presence of sperm was taken to indicate day " 0 " of gestation. "Sperm-positive" rats were individually caged and maintained at $25^{\circ} \mathrm{C}$, in a facility with a $12-\mathrm{h}$ light-dark cycle.

The animals were randomly assigned to three groups: control, pair-fed, and smoke-exposed. The control group was allowed free access to water and food. Except for daily determination of food intake and body weight, no other manipulations were performed on this group.

Animals in the pair-fed group were given free access to water and fed the same average quantity of diet consumed by the smoke-exposed group. Body weight was recorded daily. In addition, these animals were exposed to fresh air in the Walton Smoke Exposure Machine following the same regimen as the smoke-exposed group.

Finally, the smoke-exposed group was given free access to water and food. Daily food intake and body weight were recorded throughout the experiment. To achieve smoke exposure, these animals were placed two at a time in a constant volume (2124 cc) smoke exposure chamber attached to the Walton Smoke Exposure Machine. This machine is an intermittent device in which a puff from three lighted cigarettes was pushed into the exposure chamber. In the typical 1 -min cycle of operation, each puff of smoke was held in the chamber for a 30-s exposure, and then the chamber was purged with fresh air for the next $30 \mathrm{~s}$. The cycle was repeated until the cigarettes were consumed, 
usually in $7 \mathrm{~min}$. This exposure was repeated continuously every $1 / 2 \mathrm{~h}$ from $9 \mathrm{AM}$ to $5 \mathrm{PM}$ from $\mathrm{d} 5$ to $\mathrm{d} 20$ of gestation.

On d 21 of gestation, fetuses, and placentas were removed by cesarean section. After gross examination for external malformations, the fetuses were weighed and dissected. The fetal brain liver, and lungs, as well as the placenta were weighed and immediately frozen for later analysis of nucleic acid content. In order to perform this analysis, the fetus closest in body weight to the mean body weight of the litter was taken as representative for the litter. DNA and RNA were extracted serially by the Schmidt-Tannhauser method (18) as modified by Fleck and Munro (4).

To assure adequate smoke exposure, a pilot test was conducted before the experiment. This test was designed to measure the percentage of carbon monoxide saturation of hemoglobin under smoke exposure conditions. For this purpose, several rats exposed to tobacco smoke in a situation similar to that of the smoke-exposed group were sacrificed at regular and defined intervals during a 24-h period. Blood was removed from the abdominal aorta and analyzed for carbon monoxide saturation using the IL 282 CO-Oximeter. From these results it was concluded that in the present study the blood carbon monoxide saturation in the smoke-exposed group was maintained between 10-20\% from 9 AM to 5 PM. After the last smoke exposure for the day, all evidence of carbon monoxide in blood disappeared within $1 \mathrm{~h}$.

Statistical analysis. Differences between groups were analyzed using the Student's $t$ test. Results were considered statistically significant when $P$ was less than 0.05 .

\section{RESULTS}

Mean daily food intake from d 5 to $\mathrm{d} 21$ of gestation was $15 \mathrm{~g}$ for the smoke-exposed group (and consequently for the pair-fed group). For the control group, the mean daily food intake was $20 \mathrm{~g}$. Mean litter size for the three groups combined was 12.5 with no statistically significant difference between groups (Table 1). There were no resorbed fetuses nor fetal external malforma-

Table 1. Number of dams, litter size, and fetal weight for all animal groups $(\bar{x} \pm S E M)$

\begin{tabular}{lccc} 
Animal group & $\begin{array}{c}\text { No. of } \\
\text { dams }\end{array}$ & Litter size & $\begin{array}{c}\text { Fetal weight } \\
(\mathrm{g})\end{array}$ \\
\hline Control & 7 & $12.2 \pm 0.18$ & $5.85 \pm 0.13$ \\
Pair-fed & 6 & $13.1 \pm 0.47$ & $5.21 \pm 0.09^{*}$ \\
Smoke-exposed & 5 & $12.2 \pm 0.70$ & $4.60 \pm 0.16^{*} \dagger$ \\
\hline
\end{tabular}

* Significantly different from control, $P<0.05$.

+ Significantly different from pair-fed, $P<0.05$. tions in any group. Fetal weight was significantly reduced in both pair-fed and smoke-exposed groups compared with the control group. There was also a significant reduction in fetal body weight of the smoke-exposed group in comparison with the pair-fed group (Table 1).

In the analyses of the brain, significant decreases were found in total brain weight of the pair-fed and the smoke-exposed groups, compared with the control group. Total brain weight of the smoke-exposed and pair-fed groups did not differ. In addition, there were no significant differences, in brain nucleic acid content or in the weight/DNA ratio among the three groups (Table 2).

The liver analyses revealed a significant decrease in weight and RNA content in the pair-fed pups compared with controls. When comparing the smoke-exposed group with the control group, all the study variables showed a significant decrease. There was also a significant decrease in liver weight and total content of RNA between the smoke-exposed group and the pair-fed group. In contrast, DNA content was not significantly reduced (Table 2 ).

In the analyses of the lungs, except for a borderline decrease in DNA content, no other significant difference was found between the pair-fed group and the control group; however, when comparing the smoke-exposed group with either the pairfed or the control group, both lung weight and nucleic acid content were found to be markedly decreased (Table 2). Organ weight, expressed as a percentage of total body weight, shows that the greatest percentage change occurred in fetal lung weight (Table 3).

Finally, placental analyses showed no significant differences between the groups for all the variables studied, although there was a clear trend toward a decrease in weight, in RNA, and in the weight/DNA ratio, when smoke-exposed animals were compared with the pair-fed group (Table 2).

\section{DISCUSSION}

The present results document a reproducible animal model for studying the influence of maternal smoking on fetal growth in the rat. Using an automatic smoke exposure machine certainly makes the procedure highly versatile as well as accurate and reproducible. Among the various advantages of this machine are

Table 3. Organ weight as a percentage of total body weight

\begin{tabular}{lccc}
\hline Animal group & $\begin{array}{c}\text { Brain } \\
(\%)\end{array}$ & $\begin{array}{c}\text { Liver } \\
(\%)\end{array}$ & $\begin{array}{c}\text { Lung } \\
(\%)\end{array}$ \\
\hline Control & 3.8 & 8.3 & 2.6 \\
Pair-fed & 3.7 & 8.0 & 2.8 \\
Smoke-exposed & 4.0 & 7.5 & 2.3 \\
\hline
\end{tabular}

Table 2. Fetal brain, liver, lung and placenta weight, nucleic acid content, and weight/DNA ratio for all animal groups ( $\bar{x} \pm$ SEM)

\begin{tabular}{|c|c|c|c|c|}
\hline Animal group & Weight (mg) & $\mathrm{DNA}(\mathrm{mg})$ & RNA (mg) & Weight/DNA ratio \\
\hline \multicolumn{5}{|l|}{ Brain } \\
\hline Control $(n=7)$ & $221 \pm 9.1$ & $0.59 \pm 0.03$ & $0.69 \pm 0.03$ & $376 \pm 11$ \\
\hline Pair-fed $(n=6)$ & $193 \pm 5.2^{*}$ & $0.53 \pm 0.01$ & $0.64 \pm 0.01$ & $338 \pm 17$ \\
\hline Smoke-exposed $(n=5)$ & $184 \pm 5.4^{*}$ & $0.53 \pm 0.01$ & $0.63 \pm 0.02$ & $361 \pm 16$ \\
\hline \multicolumn{5}{|l|}{ Liver } \\
\hline Control $(n=7)$ & $491 \pm 20$ & $1.34 \pm 0.03$ & $3.43 \pm 0.09$ & $365 \pm 90$ \\
\hline Pair-fed $(n=6)$ & $417 \pm 10^{*}$ & $1.20 \pm 0.05$ & $3.08 \pm 0.12^{*}$ & $349 \pm 13$ \\
\hline \multicolumn{5}{|l|}{ Lungs } \\
\hline Control $(n=7)$ & $155 \pm 6.7$ & $0.82 \pm 0.02$ & $0.67 \pm 0.02$ & $191 \pm 11$ \\
\hline Pair-fed $(n=6)$ & $147 \pm 2.0$ & $0.70 \pm 0.03^{*}$ & $0.63 \pm 0.02$ & $211 \pm 90$ \\
\hline Smoke-exposed $(n=5)$ & $108 \pm 8.0 * \dot{T}$ & $0.57 \pm 0.04 * \dagger$ & $0.49 \pm 0.03^{* \dagger}$ & $189 \pm 60$ \\
\hline \multicolumn{5}{|l|}{ Placenta } \\
\hline Control $(n=7)$ & $604 \pm 46$ & $1.02 \pm 0.04$ & $2.14 \pm 0.08$ & $588 \pm 37$ \\
\hline Pair-fed $(n=6)$ & $544 \pm 41$ & $0.92 \pm 0.03$ & $2.03 \pm 0.08$ & $583 \pm 34$ \\
\hline
\end{tabular}

* Significantly different from control, $P<0.05$.

$\dagger$ Significantly different from pair-fed, $P<0.05$. 
the rotameters for setting and measuring the flow rates of the puff air and the purge air, a self-contained air humidifier for maintaining constant relative humidity of the air breathed by the animals, a cycle timer, and a constant volume chamber for the animals. For our study, we designed a cylinder chamber made of clear plexiglas, $16 \mathrm{~cm}$ long by $13 \mathrm{~cm}$ diameter that minimized animal stress due to confinement, and prevented the subsequent weight loss observed in the original restraining tubes (6). In reference to smoke absorption, it should be pointed out that some constituents of the smoke may be deposited on the exposed animal and ingested in preening or absorbed through the skin to add to the dose obtained by inhalation. As expected, some degree of fetal growth retardation was found in the pairfed group as a consequence of the $25 \%$ food restriction $(1,2)$.

Two studies have been reported on the effects of chronic exposure to cigarette smoke during pregnancy in the rat, in which the authors took into consideration the effects of smoking on the caloric intake of the mother. One of the studies found no differences in fetal weight between the rats exposed to smoke and the controls (16) whereas the other study found a significant difference (8). No effort was made to quantify the degree of smoke exposure and therefore differences in dose may explain the discrepancies in the results obtained. In the latter study fetuses at day 21 of gestation in the group exposed to tobacco smoke weighed $4.3 \mathrm{~g}$ whereas those in the pair-fed group weighed $5.2 \mathrm{~g}$, a highly significant difference. The reduction in fetal weight, found in the tobacco-smoked rats, is similar to the effect of a $50 \%$ caloric restriction (10). Because the caloric restriction of the tobacco-smoked animals was only $32 \%$, it is likely that the exposure to cigarette smoke had a negative influence on fetal growth. Unfortunately, the magnitude of this effect cannot be determined because the pair-fed control rats had a smaller litter size than the tobacco-smoked rats. Although the authors of the study discount the importance of this point, our own experience and that of other workers (26) regarding the effect of litter size on the mean fetal weight of calorically deprived rats suggests that it may have influenced the results.

The present study confirms that fetal growth retardation due to maternal smoking during pregnancy is not solely the result of reduced food intake by the mother, as concluded from the significant difference in fetal weight of the smoke-exposed group and the pair-fed group where litter size was the same. The mechanism by which tobacco smoke interferes with fetal growth is unknown. A clearer understanding may be obtained through the pattern of growth retardation. The proportionate type has been produced in the rat by restricting the protein intake of the mother throughout pregnancy (24). At term, the fetuses have a $20-25 \%$ reduction in body weight and a proportional reduction in various organs including brain, heart, lungs, liver, and kidneys. These organs also have a reduced DNA content which indicates interference with the hyperplastic phase of fetal growth.

The disproportionate type of fetal growth retardation has been produced in the rat by unilateral ligation of the uterine artery on day 17 of gestation (22). This causes a reduction in blood flow to one of the horns, which is then supplied only by the ovarian artery. At term the affected fetuses have a $20-30 \%$ reduction of body weight but a normal brain weight. The weight of the various fetal organs is reduced by $40-50 \%$. The DNA content of the brain is normal, reflecting no measurable effect of the growth retardation on the cellular growth of this organ.

Although the effect of maternal smoking on fetal body and organ weight in the rat has been studied, it is impossible to determine from the available studies the type of growth retardation obtained (8). The problem derives from the fact that organ weight has not been provided and the data is expressed as percentage of control values. Comparing changes in forebrain and liver weight, the growth retardation seems to be a disproportionate one; however, comparing the percentage changes in hindbrain and liver, the growth retardation seems to be a proportionate one.

In the present study, smoke exposure of the mother affected neither fetal brain weight nor nucleic acid content whereas fetal liver and lungs showed a significant decrease in both weight and nucleic acid content. These results indicate that fetal growth retardation associated with exposure to tobacco smoke in the rat corresponds to a disproportionate type. This supports the possibility that blood flow to the uterine horns was reduced and, if so, the present data is consistent with the report of an acute decrease on uteroplacental blood flow after cigarette smoking in healthy human volunteers (11).

At this time we do not have an explanation for the proportionally greater effect of the smoke exposure on the fetal lungs. A recent study on the effects of fetal growth and development in rats with continuous exposure to low level carbon monoxide ( 30 or $90 \mathrm{ppm}(\mathrm{CO})$ and low oxygen atmosphere $\left(13 \% \mathrm{O}_{2}\right)$ found that fetal body growth was unaffected by $\mathrm{CO}$ inhalation but was significantly reduced, approximately $13 \%$, by the low oxygen atmosphere (5). Furthermore, the mean fetal lung weight of the group exposed to $30 \mathrm{ppm} \mathrm{CO}$, was $17 \%$ lower than that of controls and $24 \%$ lower in the group exposed to $90 \mathrm{ppm} \mathrm{CO}$. How carbon monoxide interferes with fetal lung growth is unknown. It would be interesting to study the dynamics of fetal lung fluid production and its retention within the future airways, and also to characterize fetal breathing movements in association with maternal smoking because these functions are considered to be major determinants of fetal lung growth (23). Of note, injection of nicotine into pregnant ewes resulted in a fall of uterine blood flow leading to transient fetal hypoxemia and a reduction in the incidence of fetal breathing movements (12).

Finally, the present results also indicate that maternal tobacco smoke exposure induced fetal growth retardation without placental growth retardation, similar to the effects of uterine artery ligation in the rat (22). This finding further suggests the possibility of reduced uterine blood flow in the smoke-exposed animals.

\section{REFEREVCES AVD NOTES}

1. Berg. B. N.: Dietary Restriction and Reproduction in the Rat. J. Nutr.. 87: 344 (1965)

2. Chow, B. F, and Lee, Chi-jen: Effect of dietary restriction of pregnant rats on body weight gain of the offspring. J. Nutr. 82: 10 (1964).

3. Essenberg, J. M. Schwind, J. V., and Patras, A. R.: The effects of nicotine and cigarette smoking on pregnant female albino rats and their offsprings. J. Lab. Clin. Med. 25: $708(1939)$

4. Fleck. A. and Munro, H. N.: The Precision of ultra-violet absorption measurements in the Schmidt-Tannhauser procedure for nucleic acid estimation. Biochim. Biophys. Acta, 55:571 (1962)

5. Garvey, D. J. and Longo. L.: Chronic low level maternal carbon monoxide exposure and fetal growth and development. Biol. Reprod.. 19:8 (1978).

6. Guering. M. R., Caton. J. E.. and Dalbey. W. E.: Animal containment vessels for nose-only inhalation bioassay exposure to tobacco smoke. In: Guering. M. R. Stokely, J. R.. Higgins, C. E. and Griffith. G. W.: Tobacco Smoke Inhalation Bioassay Chemistry p. 35 (Oak Ridge National Laboratory. Oak Ridge. Tenncssee, 1979)

7. Hamosh, M. Simon, M. R. and Hamosh. P.: Effect of nicotine on the devclopment of fetal and suckling rats. Biol. Neonate. 35: 290 (1979).

8. Haworth. J. C. and Ford. J. D.: Comparison of the effects of maternal undernutrition and exposure to cigarette smoke on the cellular growth of the Rat Fetus. Am. J. Obstet. Gynecol., 112 (5): 653 (1972).

9. Kirschbaum, T. H., Dilts. P. V.. and Brinkman, C. R.: Some acute effects of smoking in sheep and their fetuses. Obstet. Gynecol.. 35 (4): 527 (1970).

10. Lederman, S. A. and Rosso. P.: The effects of protein and carbohydrate supplements on fetal and maternal weight and on body composition in food restricted rats. Am. J. Clin Nutr. 33.1912(1980)

11. Lehtovirta. P. and Forss, M.: The acute effect of smoking on uteroplacental blood flow in normotensive and hypertensive pregnancy. Int. J. Gynaecol. Obstet.. 18:208(1980).

12. Manning. F: Walker. D.. and Feverabend $C$. The effect of nicotine on fetal breathing movements in conscous pregnant ewes. Obstet. Gvnecol. $5215 \%$ $563(1978)$.

13. Miller, H. C.. Hassanein, K... and Hensleigh, P. A.: Fetal growth retardation in relation to maternal smoking and weight gain in pregnancy. Am. J. Obstet. Gynacol.. 125: 55 (1976).

14. Nishimura, $\mathrm{H}$. and Nakai. K. Developmental anomalies in offspring of pregnant mice treated with nicotine. Science. 127: 877 (1958).

15. Peters. D. A. V.. Taub. H... and Tang. S.: Postnatal effects of maternal nicotine exposure. Neurobehav. Toxicol. 1: 221 (1979).

16. Reznik. C. and Marquard. C.: Effect of cigarette smoke inhalation during pregnancy in sprague-dawley rats. J. Environ. Pathol. Toxicol., 4(5-6): 141 (1980).

17. Rosso, P. and Winick. M.: Intrauterine growth retardation. A new systematic 
approach based on the clinical and biochemical characteristics of this condition. J. Perinat. Med. 2: 147 (1974).

18. Schmidt, G. and Tannhauser, S. J.: A method for the determination of deoxvribonucleic acid, ribonucleic acid, and phospho-proteins in animal tissue. J. Biol. Chem.. 161:83 (1945)

19. Suzuki, K.. Horiguchi, T. Comas-Urrutia, A. C. Mueller-Heubach, E.. Morishima. H.. and Adamsons. K.: Pharmacology effects of nicotine upon the fetus and mother in the rhesus monkey. Am. J. Obstet. Gynecol.. 11/18) 1092 (1971).

20. U.S. Department of Health. Education and Welfare: Pregnancy and Infant Health. Reprinted from "Smoking and Health: A Report of the Surgeon General". Chap. 8. p. 11 (1979).

21. Wagner. B. and Chouroulinkov, I.: The effect of cigarette smoke inhalation upon mice during pregnancy. Rev. Eur. Etud. Clin. Biol., 18: 943 (1972).

22. Wigglesworth. J. S.: Experimental growth retardation in the foetal rat. J. Path. Bact. 88 (l): 1 (1964).

23. Wigglesworth, J. S.: The effect of placental insufficiency on the fetal lung. J. Clin. Pathol. (suppl), 10:27 (1976)
24. Winik $M$. Cellular growth of the placenta as a indicator of abnormal fetal growth. In: K. Adamsons Diagnosis and Treatment of Fetal Disorders. pp 83-101 (Springer-Verlag. New York 1969).

25. Younoszai, M. K.. Peloso, J., and Haworth, J. C.: Fetal growth retardation in rats exposed to cigarette smoke during pregnancy. Am. J. Obstet. Gynacol. 104: 1207 (1969)

26. Zambrana. M. A. and Greenwald. G. S.: Effects of fetal, ovarian and placental weight of various number of fetuses in the rat. Biol. Reprod.. 4:216 (1971).

27. The authors thank Mr. Frank Mallavo for technical assistance.

28. Requests for reprints should be addressed to: Dr. Jorge A. Bassi. Columbia University, College of Physicians and Surgeons. Institute of Human Nutrition, 630 West 168th Street, Black Building--Room 262. New York, NY 10032

29. This research was supported by the National Institutes of Health. Grant No. HD- 13063 .

30. Received for publication August 31, 1982

31. Accepted for publication May 9, 1983.

\title{
Detection of the Cystic Fibrosis Protein by Isoelectric Focusing of Serum and Plasma
}

\author{
R. GRATAROli. O. GUY-CROTTE, C. GALABERT, AND C. FIGARELla ${ }^{(15}$ \\ Unité de Recherches de Pathologie Digestive, INSERM U-31, 46. Boulevard de la gave, 13258 \\ Marseille Cedex 09, France
}

\section{Summary}

We used the isoelectric focusing method developed by Wilson to analyze serum from individuals homozygous or heterozygous for cystic fibrosis. The presence of cystic fibrosis protein (CFP) was found in 37 out of 52 homozygous and 24 out of 34 heterozygous patients, which leads to a frequency of $71 \%$ for both families. Five out of $\mathbf{2 4}$ controls were found positive. The same study, performed on 26 plasma samples collected from the same patients, demonstrated that the detection of CFP is possible in plasma as well as in serum. Our results confirm the presence of a protein "marker" of CF in serum, but also underlines the lack of sensitivity of the isoelectric focusing technique to be used for diagnosis.

\section{Abbreviations}

CFP, cystic fibrosis protein

IEF, isoelectric focusing

Cystic fibrosis, characterized by a generalized metabolic disorder, is one of the most prevalent genetic diseases in the Caucasian population. An incidence of 1 in 2000 live births has been reported (3), and approximately 1 in 20 of the population is a carrier of the gene or heterozygote (8).

In 1973, Wilson et al. (8) detected a "cystic fibrosis factor" now designated "cystic fibrosis protein" in serum using IEF in thin layer polyacrylamide gels. Other studies from this laboratory $(9,11)$ characterized this CFP as having a $\mathrm{pI}$ of 8.4 , a molecular weight between $3500-10,000$, and a close association with IgG in serum. The importance of these findings prompted different laboratories to reproduce this IEF technique but with widely varying success $(2,5,7)$. Recently, Nevin et al. (4) confirmed the CFP frequency reported by Wilson using the same IEF technique. Because of several unsuccessful reports, another set of experiments to confirm the presence of this protein in serum was necessary. Furthermore, the protein had never been characterized in plasma. Only Wilson recommended that samples obtained from heparinized or citrated blood not be used (9); therefore, it is of interest to study the presence of CFP in plasma and serum from the same patients for a further understanding of the nature of CFP, and to eliminate the possibility of the origin of CFP by proteolysis during blood clotting.

\section{MATERIALS AND METHODS}

Material. Sera from $52 \mathrm{CF}$ patients were supplied by J. P. Chazalette (Giens) and R. Gilly (Lyon). Diagnosis of the disease was established by clinical criteria and an abnormal sweat test. Sera from 34 obligate heterozygotes and 24 controls were studied in parallel.

Preparation of sera and plasma. All sera were carefully collected as described by Wilson et al. (9). After collection, all samples of venous blood were immediately cooled at $4^{\circ} \mathrm{C}$ and allowed to clot in glass tubes for $4-6 \mathrm{~h}$. The samples were then centrifuged at $1700 \mathrm{~g}$ for $10 \mathrm{~min}$ at $4^{\circ} \mathrm{C}$ and the serum was transferred by aliquots into plastic tubes, then frozen and stored at $-75^{\circ} \mathrm{C}$

Plasma $(5 \mathrm{ml})$ from the same patients $(12 \mathrm{CF}$ patients, nine heterozygotes, and five controls) were collected in tubes containing $25 \mu \mathrm{l}$ heparin $(50,000 \mathrm{IU})$ and immediately centrifuged at $400 \mathrm{~g}$ for $5 \mathrm{~min}$, then at $3000 \mathrm{~g}$ for $10 \mathrm{~min}$ at $4^{\circ} \mathrm{C}$. After centrifugation, plasma samples were stored as described for serum.

$I E F$. IEF was performed in thin layer polyacrylamide gels 